\title{
Article
}

\section{Agency in the absence of reason- responsiveness: The case of dispositional impulsivity in personality disorders}

\author{
Ayob, Gloria Leila \\ Available at http://clok.uclan.ac.uk/33300/ \\ Ayob, Gloria Leila ORCID: 0000-0001-5374-2161 (2016) Agency in the \\ absence of reason-responsiveness: The case of dispositional impulsivity in \\ personality disorders. Philosophy, Psychiatry, \& Psychology, 23 (1). pp. 61-73. \\ ISSN 1071-6076
}

It is advisable to refer to the publisher's version if you intend to cite from the work. http://dx.doi.org/10.1353/ppp.2016.0004

For more information about UCLan's research in this area go to http://www.uclan.ac.uk/researchgroups/ and search for <name of research Group>.

For information about Research generally at UCLan please go to http://www.uclan.ac.uk/research/

All outputs in CLoK are protected by Intellectual Property Rights law, including Copyright law. Copyright, IPR and Moral Rights for the works on this site are retained by the individual authors and/or other copyright owners. Terms and conditions for use of this material are defined in the policies page.

\section{CLoK}

Central Lancashire online Knowledge www.clok.uclan.ac.uk

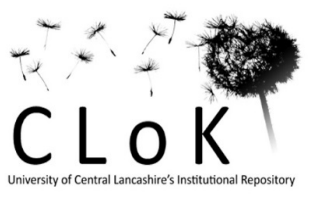


Title of manuscript:

Agency in the absence of reason-responsiveness:

The case of dispositional impulsivity in personality disorders

Author of manuscript:

Dr. Gloria Ayob

Author affiliation:

Senior Lecturer in Philosophy and Mental Health

School of Health

University of Central Lancashire

Author correspondence:

School of Health

University of Central Lancashire

Preston PR1 2HE

United Kingdom

(Email address: GLAyob@uclan.ac.uk)

Manuscript word count:

Without endnotes: 7216 words

With endnotes: 8458 words 


\begin{abstract}
It has been argued recently that persons diagnosed with a personality disorder (PD) ought to be held responsible for their actions because these actions are voluntary. (Pickard 2011, this journal). In what follows, I argue that this claim is grounded in a conception of voluntary action that is too coarse-grained to provide an adequate understanding of the structure of agency in persons diagnosed with PD. When the concept of voluntary action and that of behaviours typical of PD are examined more carefully, the claim that PD behaviours are voluntary turns out to be tenuous in at least two ways. Firstly, it becomes apparent that the grounds provided by Pickard do not conclusively establish that PD behaviours are voluntary. Secondly, a more refined conception of voluntary agency helps us to appreciate that, if indeed PD behaviours are voluntary, such behaviours seem at best to be voluntary in an anaemic and limited sense - a sense that is quite distinct from the ordinary sense in which we speak of actions being voluntary.
\end{abstract}


Agency in the absence of reason-responsiveness:

The case of dispositional impulsivity in personality disorders

\section{Introduction}

It has recently been argued that persons diagnosed with a personality disorder (PD) ought to be held responsible for their actions because these actions are voluntary. Defending this claim, Hannah Pickard contends that exercising choice and control are definitive of voluntary action, and that the behaviours that are constitutive of PD are behaviours over which we have choice and control. Thus PD behaviours are voluntary, and on this basis, their agents can be held properly responsible for this type of behaviour (Pickard 2011, 2013). In what follows, I examine this claim with reference specifically to agents who display impulsive behaviour, where this behaviour is taken to be diagnostic of Antisocial Personality Disorder (APD) and Borderline Personality Disorder (BDP). I aim to establish the claim that the impulsive acts committed by human agents in this specific subgroup are not voluntary actions, contrary to what Pickard suggests. The view that such acts are voluntary rests on a conception of voluntary action that is too coarse-grained to provide an adequate understanding of the structure of agency from which these impulsive acts arise. The persistent and pervasive quality of impulsivity that is characteristic of this subgroup of APD and BPD agents will be central to the discussion in this paper. Therefore, I will speak of 'PD-impulsive behaviours' to distinguish them from impulsive acts committed by ordinary (non-clinical) agents without a diagnosis of personality disorder, acts that are neither a pervasive nor persistent characteristic of their lives. ${ }^{i}$ 
I will argue that when the concept of voluntary action and that of impulsive behaviours typical of PD are examined more carefully, the claim that PD-impulsive behaviours are voluntary turns out to be tenuous in at least two ways. Firstly, it becomes apparent that the grounds provided by Pickard do not conclusively establish that PD-impulsive behaviours are voluntary. I will develop this observation in the Section III below. Secondly, a more refined conception of voluntary agency helps us to appreciate that, if indeed PD-impulsive behaviours are voluntary, such behaviours seem at best to be voluntary in an anaemic and limited sense - a sense that is quite distinct from the ordinary sense in which we speak of actions being voluntary. To establish this point, I present a reason in Section IV for thinking that PD behaviours are not voluntary, at least not in the sense that entails culpability (it is in this sense that Pickard uses the term 'voluntary action', since she takes the establishment of PD behaviours as voluntary to be sufficient for holding PD agents responsible for this behaviour). The discussion in Sections IV and $\mathrm{V}$ is informed by a widely shared view of what it is to be a culpable moral agent, namely that it involves a form of normative competence. The specific form of competence involved is, as Robert Jay Wallace describes it, "the ability to grasp and apply moral reasons, and to govern one's behaviour by the light of such reasons." (Wallace 1988:2). This approach towards the question of culpability — according to which the emphasis is laid on an agent's responsiveness to reasons - was articulated and made prominent in recent times by Peter Strawson (Strawson 1974). It continues to shape thinking about moral culpability.

If the claims in Sections IV-V are right, then it turns out that although the structure of agency in agents demonstrating PD-impulsivity might in some ways resemble the structure of ordinary human agency, it differs in important respects, respects that bear upon the question of whether PD-impulsive behaviours are genuinely voluntary in the way that ordinary intentional action is. Crucial to this insight is the availability of a sufficiently refined conception of voluntary action. Before I embark on this argument, I will sketch out two case vignettes in the next section 
to underscore the persistent and pervasive quality of the impulsive behaviour demonstrated in PD-impulsive agents.

II. Impulsivity in personality disorders: a clinical characterisation and case vignettes

As with the other Cluster-B personality disorders (histrionic and narcissistic), APD and BPD are diagnostically defined in terms of several criteria, disjunctively specified. Taken in conjunction with four other criteria in BDP, and two other criteria in APD, the criterion of impulsivity is a sufficient but not a necessary feature of both categories of personality disorder. This means that although impulsivity is not co-extensive with being diagnosed with a personality disorder, it is nonetheless a distinctive feature of a subgroup of persons diagnosed with APD and BPD.

Impulsivity is a diagnostic criterion not unique to the personality disorders. It is listed in Attention Deficit Hyperactivity Disorder (ADHD) and bipolar disorder, amongst others (APA 2014). But the impulsivity that is taken to be diagnostic of APD and BPD is distinctive in two ways. First, it is a persistent and pervasive feature of a person's behaviour. This serves to distinguish it from the impulsivity displayed in a manic episode in a subject diagnosed with Bipolar Disorder. Second, the concept of impulsivity used to diagnose APD or BPD refers not to attentional impulsivity (at least, not primarily), but specifically to impulsive acts that express poor self-control and an inability to engage in planning (which involves a degree of cognitive complexity). ${ }^{\text {ii }}$ Taken together, these features motivate the inquiry below into the claim that PDimpulsive acts are voluntary. Before proceeding, it may be helpful to have a case vignette to illustrate the impulsivity that is distinctive of APD and BDP. 


\section{Vignette 1: BPD}

Ms. A., a 27-year-old woman, presented for treatment at the insistence of her husband. The patient admitted to frequent violent arguments with her husband, family, coworkers, and, often, strangers. She had lost many jobs because of her mood lability and intense, inappropriate anger. She was also violent with her husband during arguments over seemingly trivial matters. For example, Ms. A. hit her husband's head against the steering column when he became lost on the way to a movie theatre. She had gotten into similarly violent arguments with her sister and mother and was losing her temper with her 3-year-old daughter, slapping her on several occasions. Ms. A. would usually feel guilty after these events and had attempted suicide several times. (Kavoussi and Coccaro 1996: 131).

\section{Vignette 2: Conduct disorder leading to APD}

From childhood, Bill's relationships were characterised by conflict. When things did not go his way, Bill's response was simple and direct - a fight. As he grew up, his antisocial and daredevil behaviour escalated. In an early episode, Bill instigated a 'window-breaking competition', in which he goaded four friends into throwing rocks through windows in their neighbourhood. While his friends went along with this with fear and trepidation, Bill showed no signs of apprehension. Indeed, he seemed ecstatic and was bubbling over with enthusiasm. His only negative reaction of the evening was directed toward one of his friends for 'missing' several windows. Bill graduated from window-breaking to petty theft. He would steal anything — candy, fruit, clothing — not just things he wanted. In fact, he often threw away the things he had stolen. He was eventually apprehended by the police for driving drunk in a car he had stolen, smashing 
it into a telephone pole. He was sent to reform school, where he spent 2 years. When he was released, Bill appeared to his brother changed. He now seemed to be a real criminal. Car thefts were no longer for joyrides but for profit. He dropped out of school, and was indifferent to his criminal behaviour. Bill's brother reports that when he tried to talk to him, even the charade of shame and guilt was gone. Bill expressed an "I'll take what I want when I want" attitude. Shortly after his 18th birthday, Bill attempted a bank robbery, armed with a .38-caliber automatic pistol. Bill was driving a stolen car. On seeing what he thought was a bank, he impulsively decided to rob it. In his rush, he had actually undertaken to rob an office of the electric company. Once inside, although recognizing his mistake, he decided to go through with the holdup anyway and had several tellers empty their cash drawers into a sack. A patrol car passed by the office as the holdup was in progress, and seeing what was happening, the policemen stopped to investigate. Bill ran out of the office directly into the police and was easily arrested. He was tried, convicted, and sentenced to 10 years in the penitentiary. (Excerpted and adapted from Oltmanns et al 2012: 297-300)

The impulsivity displayed by Bill and by Ms. A respectively is expressive of poor self-control and an inability to act on the basis of strategic thinking and planning, impairments that stretch over an extended period of time. The severity of these impairments is reflected in the significance of the goods that are lost by the agent either as a direct or an indirect result of his/her dispositional impulsivity: job losses, marital breakdown, terrorised offspring, even the loss of personal liberty itself. Determining whether the impulsive acts that arise specifically from this context of severe dispositional impulsivity are expressive of voluntary agency is the question that will concern me in what follows. 


\section{Are PD behaviours voluntary?}

I will begin by briefly reviewing Pickard's claim that PD behaviours are voluntary and that their agents can thus be held responsible for those behaviours. In support of the claim that the behaviours constitutive of PD are voluntary, Pickard divides up behaviour into two kinds: mere bodily movements (e.g. automatic reflexes) and action, which is voluntary by definition. That is, for Pickard it is the fact that a piece of behaviour is voluntarily performed that makes it an action, as opposed to a mere bodily movement. So the condition of voluntariness demarcates the boundary between the two kinds of behaviour. In turn, voluntariness is defined by Pickard in terms of the notions of choice and control: an action is a piece of behaviour over which we have a choice and thus over which we exercise control. (Pickard 2011: 212)

Having drawn the distinction between voluntary action and mere bodily movement in this way, Pickard then observes that the behaviours that are constitutive of PD are not mere bodily movements. The following list of behaviours typical of PD illustrates the point intuitively: exploiting others, demanding attention, lashing out in anger, drinking or taking drugs, selfharming, or committing a crime. Based on the binary distinction between voluntary action and mere bodily movements noted above, and reinforcing the intuitive point by citing evidence that PD subjects "routinely choose to behave otherwise when they have the incentive and motivation to do so," Pickard concludes that these behaviours are voluntary. (ibid: 212) ${ }^{\text {iii }}$

Notice that several of the behaviours mentioned in this list are often done impulsively: lashing out in anger, drinking, self-harming, committing a crime (assault, theft). Indeed, as noted in the previous section, impulsivity is an important diagnostic criterion in borderline and antisocial personality disorders. But impulsive behaviour sits problematically in Pickard's binary distinction between voluntary action and mere bodily movements. ${ }^{\text {iv }}$ On the one hand, impulses 
or urges are things that humans can suppress, and so they seem to be things that it is possible to control. Furthermore, in contrast with automatic reflexes (which are mere bodily movements par excellence), impulses and urges often have an intentional content, e.g. the urge to smoke a cigarette, or the impulse to hit a particular person. Both points speak in favour of the claim that behaving on an impulse or urge amounts to a voluntary action. On the other hand, however, urges and impulses have struck many people as being states that aren't always controllable. The general consensus in the philosophical literature seems to be that one can be compelled by one's impulses or urges in a way that renders the ensuing behaviour involuntary. Compulsions are taken to be behaviour of this sort. (For a sampling of sources that take this view about compulsions, see Fischer and Ravizza 1998, Smith 2003).

In light of the fact that there are considerations that speak both for and against the idea that impulse-driven behaviour is voluntary, what should we say of the impulsive behaviour that is taken to be diagnostically criterial in antisocial PD (APD) and borderline PD (BPD)? If we judge this type of behaviour to be similar to compulsions (could they perhaps even be an instance of compulsion?), then we ought to say they are involuntary, if we hold that compulsions are involuntary. Or should we place the emphasis on the fact that humans, as a species, have the capacity to suppress impulses and urges - and insist on saying that the impulsive behaviour in PD is voluntary insofar as they are expressive of impulses, and impulses are the kinds of thing we (as a species) have the capacity to suppress?

In order to determine the answer to this question, it will be helpful to begin by setting impulses and urges in the context of the main behavioural types that have been explored in the philosophical literature. This will help us to gain a better sense of the space of available options, and therein to arrive at a more refined understanding of the concept of voluntary action in terms of which to address this question about the volitional nature of impulses and urges. So consider the following types of behaviour: 
(i) Accidents (e.g. tripping over a curb).

(ii) Automatic reflexes (e.g. sneezing upon entering a dusty environment, automatic eye-blinking, the classic knee-jerk reaction, reaching for a fragile object that is about to topple over).

(iii) Urges and impulses with no intentional content (e.g. the urge to move one's legs in Restless Leg Syndrome).

(iv) Urges and impulses with intentional content (e.g. the urge to smoke a cigarette or the impulse to hit a particular person).

(v) Actions that are determined by belief-desire pairings.

(vi) Full-blown autonomous actions.

Accepting Pickard's choice-and-control definition of voluntary action, we can straightforwardly characterise the first and final two cases. The first two types of behaviour are straightforward instances of mere bodily movements: the very notion of an accident, or of an automatic reflex, excludes the notion of exercising control (let alone choice) over the behaviour that constitutes the reflex or the accident. On the other end of the spectrum are actions that are determined by belief-desire pairings and full-blown autonomous actions. Behaviour in both these kinds of case involves making choices and the exercise of control (i.e. control both over one's body and one's environment, physical and social). Thus both types of behaviour appear to be voluntary actions by definition, at least in the terms set out by Pickard. (For the sake of comprehensiveness, it is worth distinguishing the two kinds of behaviour for the following reason: while it is possible for an agent to be alienated from his own actions in the case of Type-(v) behaviour, the notion of full-blown autonomous action rules out this possibility as a matter of definition (for the locus classicus on this point, see Frankfurt 1971)). ${ }^{\mathrm{v}}$

So behaviours Type-(i) and Type (ii) are, by definition, not voluntary actions; and behaviours Type-(v) and Type-(vi) are, by definition, voluntary actions. But Pickard's definition of 
voluntary action does not give us a straightforward way of characterising the two behavioural types in the middle, i.e. the impulses and urges. That humans have the capacity to suppress impulses/urges tells us nothing about the exercise of choice and control in any particular instance of an impulse- or urge-driven behaviour, given the existence of compulsions. The fact that compulsions exist makes the statement that humans have the capacity to suppress urges look rather like the statement that humans have the capacity to run a four-minute mile: certain humans, in running, will be exercising this capacity; but most will not. A person's membership in the human species alone does not guarantee that when the person runs, she or he will be exercising the capacity to run a four-minute mile. Likewise, in light of the existence of compulsions, only the following conditional claim about impulse- and urge-driven behaviour seems warranted: when the capacity to suppress an impulse/urge is exercised, then the behaviour arising from the impulse/urge (whether this is suppression or expression) is voluntary; otherwise, not.

A moment's pause: can the expression of an impulse - as opposed to suppression-ever be voluntary? The following case suggests there could be: the impulse to the embrace someone. The impulse arises spontaneously, as any impulse does, and its expression (the agent's actually embracing the person) could be direct, i.e. not involving strategic reasoning or reflective evaluation. When done in a friendly manner, and is welcomed by the recipient of the embrace, it could be the case that the embrace is a voluntary action. Our judgement about whether it is will depend, interestingly, on whether we believe the agent is dispositionally impulsive or not. If we think she isn't, we would be more inclined to conceptualise her embrace as a voluntary action. If on the other hand we know that she is systematically impulsive, this weakens the inclination to conceive of the embrace in these terms. Exactly why our judgements are dependent at least to some extent on the agent's character or personality is an interesting and 
important question, and the discussion in Section IV provides the beginning of a possible answer to this question.

Taking stock of the main claim I have been making so far: the fact that impulses and urges can be suppressed (by all people, at least some of the time; and by some people, e.g. seasoned meditators, perhaps all the time) does not yet establish that each and every token of impulseor urge-based behaviour constitutes a voluntary action. This is because there exist tokens of such behaviour that are widely held to be beyond the agent's control, and are thus not instances of behaviour with respect to which the agent can exercise choice (i.e. compulsion). So membership in a particular category of mental states with respect to which it is possible to exercise choice and control—namely, impulses/urges—is insufficient to establish voluntariness. Whether or not the impulsive behaviours that are diagnostically criteria of APD and BPD signify compulsions - or are similar to compulsions in important respects - is something that needs careful thinking about. I consider to it to be a live possibility, but I take no stance on the question in this paper. All that is being pointed out is that, contrary to what Pickard suggests, the mere fact that these impulsive behaviours are not brute bodily movements does not by itself provide conclusive grounds for holding that they amount to actions done voluntarily. In the next section, I put forward one reason for thinking that the impulsive behaviours that are constitutive of PD are not voluntary actions - at least, not in a sense that would entail culpability.

IV. A reason for thinking that PD-impulsive behaviours are not (substantively) voluntary 
The discussion in this section and the next is informed by a widely shared view of what it is to be a culpable moral agent. According to the view, being a culpable agent involves "the ability to grasp and apply moral reasons, and to govern one's behaviour by the light of such reasons." (Wallace 1988:2). If culpability is construed as essentially involving normative competence, this entails that the concept of voluntary action denotes a capacity (or a cluster of capacities). In fact this condition on the concept of voluntary action is contained implicitly in the choiceand-control definition of voluntary action presented by Pickard, since the notion of making a choice - and exerting choice-informed control over one's behaviour-denotes the exercise of certain capacities, at least some of which must be characterised in terms of the notion of rationality if the choice is to be recognisable as such. The connection between the concept of voluntary action and the exercise of rational capacities is thus a conceptual one. ${ }^{\mathrm{vi}}$

In view of this, what is striking about PD agents who are disposed to impulsive behaviour is the fact that they systematically make poor choices. Because an action done voluntarily consists in an exercise of rational capacities that underpin choice-making, the fact that PD-impulsive agents make not just poor choices but dispositionally poor choices becomes a significant datum in determining whether or not the behaviours that are constitutive of PD-impulsivity can rightly be considered to be voluntary actions. Simply put, the datum raises the question about whether the rational capacities that underpin choice-making are in fact present in PD-impulsive agents. ${ }^{\text {vii }}$ If they aren't, this casts in an altogether new light the fact that the PD-impulsive agent seems able on the odd occasion to suppress an impulse or an urge. What features of the environment (physical and social) are they tracking, and are these features ones that are similar to, or different from, features tracked by an agent with well-developed rational capacities features the reliable tracking of which is enabled by precisely having those capacities? In plainer terms, but one which is problematic for a reason I'll note immediately below, the question is this: are the reasons cited by the PD agent for suppressing an impulse, on the odd 
occasion that he manages this, similar to the reasons cited by the ordinary agent (one whose rational capacities are well developed) when she suppresses an impulse?

My caution for formulating the question in terms of reason-giving is this: it suggests that, insofar as the PD-impulsive agent is able to give reasons for her choice (to suppress an impulse), she must possess rational capacities, just like non-clinical adults do. But this suggestion begs the very question I am trying to articulate, which is underscored by the following consideration: empirical studies show that certain non-human mammals-including (non-human) primates and the domestic dog-manifest an ability to delay gratification. (Leonardi et al 2012). This is a remarkably sophisticated exercise of choice, one that presupposes an intelligent tracking of features of the environment that are strategically relevant to the creature's present concerns - and interestingly, one that involves the suppression of impulses/urges. Still, in spite of their ability to delay gratification, we would hesitate to describe domestic dogs as rational agents. We may grant that the delaying of gratification on the part of a dog is an exercise of strategic rationality, but we would hesitate to view dogs as rational agents as such. This hesitation is anchored in the fact that there is no grounds (yet, anyhow) for holding that dogs engage in reason-giving practices.

Exactly what it is to engage in reason-giving practices is a large question, but it is generally accepted that an essential part of such engagement is the agent's systematic evaluation of reasons as better or worse along various normative dimensions - e.g. epistemic, moral, prudential, conventional. There is disagreement about whether this condition should be taken to include an agent's commitment to certain substantive values, or whether the ability to evaluate reasons should be taken to refer only to the agent's ability to appraise her motivational states in light of her evaluation of reasons (whatever her substantive values are), and to exercise reflective self-control accordingly. viii There isn't a need to take a stance on this dispute in the present paper because the failure of engagement in reason-giving practices that concerns us 
here is of a specific form, i.e. the absence of systematic evaluation of reasons on the part of the agent (which both parties to the dispute agree is a basic condition of engagement in reasongiving practices). It is the absence of systematic evaluation of reasons-indeed, of any evaluation of reasons at all —on the part of a dog that discounts it from being a participant of reason-giving practices, and it is because dogs do not engage in reason-giving practices that we hesitate to view dogs as rational agents as such, even though they are able to delay gratification.

The engagement in a reason-giving practice is thus taken to be essential to the possession of the rational capacities that underpin the choice-informed control of behaviour that is definitive of voluntary action. The question being asked, therefore, is whether PD-impulsive agents can be said to engage in reason-giving practices. The fact that they can, at times, be strategically rational doesn't yet establish that they are thus engaged. It may be helpful here to explicitly distinguish between two notions of voluntary action: minimal voluntary action, which consists in the capacity to exercise control over one's behaviour in a manner that does not depend on any engagement with reason-giving practices (canine delayed gratification may count as an instance of this); and substantive voluntary action, which consists in the capacity to exercise reason-informed control over one's behaviour. While the suppression of an impulse or an urge may count as a minimally voluntary action (and we might take impulse-suppression to constitute an exercise of strategic rationality), this tells us nothing yet about whether the PD subject is engaged in reason-giving practices, and thus it tells us nothing yet about whether the PD subject's suppression of the impulse is a substantive voluntary action. This, to recapitulate, is because the systematic evaluation of reasons is an essential condition of engaging in reasongiving practices, and a sentient creature needs to be engaged in reason-giving practices to count as a rational agent in the full sense of the word. It is rational agency in this sense that underpins 
substantive voluntary action, at least as this is intuitively understood (an intuition manifest in the contrast between canine impulse-suppression and human impulse-suppression).

The PD-impulsive subject seems to fail to engage with reason-giving practices, as borne out in the fact that she makes dispositionally poor choices. Now, on the assumption that the PDimpulsive subject is innately equipped with the cognitive machinery to reflect on her own mental states, this failure to engage with reason-giving practices may come about in one of two possible ways: it may be that she systematically fails to appraise reasons aright, or it may be that, although she appraises reasons aright, she fails systematically to be appropriately motivated by those reasons. Systemic failure in either sense suggests a blindness to reasongiving practices that renders problematic the ascription of culpability - and the ascription of substantive voluntary action upon which it depends - in roughly the way that colour-blindness would render problematic the ascription of culpability for failing to engage with colourinvolving language games.

To get a better sense of the difficulty with describing the occasional impulse-suppression in PD-impulsive subjects as a substantive voluntary action, it may be useful to compare the two systemic failures just mentioned with cases in which the failures are merely occasional. Take an ordinary agent who, on a particular occasion, acts recklessly. From the observer's viewpoint, the situation is as follows: on balance, with all reasons considered and weighed up against each other, the agent should not perform an action, ø. For simplicity, I will assume that the observer appraises the reasons aright. However, on this particular occasion, the agent appraises the reasons differently, and assigns a heavier weighting to a reason (or cluster of reasons) for performing $\varnothing$, relative to the reason(s) against performing $\varnothing$. Guided by this appraisal of reasons, she acts accordingly. An example: an agent is just over the legal alcohol limit but decides that the convenience of driving home, rather than walking home and returning to pick up the car in the morning, outweighs the prudential caution against driving that is merited by 
her state of intoxication. Importantly, this failure to appraise the reasons aright is a one-off event. Generally, this particular agent does appraise reasons aright and so, on most if not all other similar occasions, her appraisal of reasons converges with that of the observer's. Guided by this appraisal, she would normally not drive home. The agent's general pattern of reasonappraisal supports the claim that she is engaged in reason-giving practices. This engagement gives us a basis for holding her responsible for being reckless, i.e. for failing to appraise reasons aright on this particular occasion. The basis for holding her responsible is precisely that she has the ability to recognise and to evaluate reasons in a way that makes her a participant in reasongiving practices. Notice that it is only by presupposing that she has this ability that I could make sense of the idea that, on this occasion, she is being reckless, rather than ignorant or blind to reasons.

Tweaking the example, suppose that rather than being reckless, the agent is weak-willed instead. That is, she agrees with the observer's appraisal of reasons in this particular situation, and concedes that she should not drive home tonight. However, she fails to be appropriately motivated by this appraisal of reasons, and instead gives in to her strong desire for convenience (against her own better judgement). So she gets in the car and drives home. Like the previous version of the example, I am assuming that this is a relatively rare event in the agent's life: generally, the she is appropriately motivated by her appraisal of reasons. What this means is that on most if not all other similar occasions, she would not have given in to her desire for convenience, but instead be guided by her better judgement. Again, the agent's general pattern of reason-responsivity (as manifest in action) supports the claim that she is engaged in reasongiving practices. This engagement is what gives us a basis for holding her responsible for being weak-willed, i.e. for giving in to a strong desire even though she herself judges the desire ought not to be acted upon. We are able to hold her responsible in this way because her motivational structure is suitably reason-sensitive. (The discussion of recklessness and weakness of will 
draws heavily on Michael Smith's analysis of the two concepts, and of the concept of compulsion, in his 2003).

The PD-impulsive subject's disposition to make poor choices - rooted at least in part in her disposition to act impulsively_-suggests that she is either blind to reasons, or that her motivational structure is not suitably reason-sensitive. Either of these impairments would suffice to render problematic ascriptions of culpability, and with it the ascription of voluntary action in the substantive sense. The problem, in a nutshell, is that it is not that the PD-impulsive subject sees what she should not do, and is receptive to the normative pull exerted by that 'should not', but then goes ahead anyway and does what she knows she shouldn't. The problem is that the PD subject may be incapable of seeing what she should not do (she may be reasonblind), or she may be incapable of understanding the normative pull exerted by the injunction not to do what she has the impulse to do (her motivational structure may be reasoninsensitive). ${ }^{\text {ix }}$ In either case, ascriptions of culpability seem to be as misplaced as they are when a colour-blind agent fails to engage in colour-involving language games (e.g. the appreciation and critique of oil paintings). In turn, if culpability entails that an action is done voluntarily in a substantive sense, then the difficulty in holding PD-impulsive subjects culpable that arises from the fact that they aren't engaged in reason-giving practices will also beset the conception of PD-impulsive behaviours as substantive voluntary actions.

We should be wary about assuming that PD-impulsive subjects are either simply reckless or weak-willed, in view of the fact that they are dispositionally impulsive. Think about what would have to be the case for a PD-impulsive subject to be considered reckless or weak-willed: she would have to show evidence of a general ability to cotton on to reasons as ordinary agents do, and a general ability to be suitably motivated by the reasons she appraises aright. But the only evidence for both these general abilities would be her pattern of behaviour over time. In other words, the structure of her entire personality would have to be different to what it actually 
is. To put the point in terms of possible worlds, the ordinary agent who is reckless would, in a nearby possible world, have converged in her appraisal of reasons with the observer's appraisal (because she has the ability to see reasons aright). The ordinary agent who is weak-willed would, in a nearby possible world, have been guided in her behaviour by her appraisal of reasons (because her motivational structure is suitably sensitive to reasons). Not so for the PDimpulsive subject: lacking either the ability to see reasons aright or a motivational structure that is suitably sensitive to reasons, much would have to change for PD subject to act differently from how she actually does. We would have to imagine that she possesses general abilities which she currently lacks; and this will involve more than just tweaking one or two details about the particular situation in which the PD subject acts as she does, e.g. the social company she happens to be in that particular evening. This degree of change would place us in a possible world that is quite distinct from our actual one: it involves, at the very least, imagining that the PD-impulsive subject has a different personality from the one she actually does. (By contrast, we can imagine that the reckless and the weak-willed agents continue to have the actual personalities that they do, in the possible worlds in which they act in a manner that is not reckless or not weak-willed). ${ }^{\mathrm{x}}$

Having distinguished the PD-impulsive subject who is disposed to making poor choices from the reckless agent and the weak-willed agent, we are now in a position to return to a question raised earlier: can the expression of an impulse can ever be voluntary? Sticking with the example earlier - of the spontaneous impulse to embrace someone-I suggested that our judgements about voluntariness are shaped largely by whether or not the agent who acts on the impulse is dispositionally impulsive. I pointed out that if she isn't, we would be more inclined to conceptualise her embrace as a voluntary action. If on the other hand she is systematically impulsive, this weakens the inclination to conceive of the embrace in these terms. The foregoing discussion suggests the beginnings of an explanation for why character or personality 
shapes our judgements about voluntariness. The agent who is not dispositionally impulsive is engaged in reason-giving practices, in the ways just outlined: she is neither reason-blind nor reason-insensitive. So when the agent acts on the impulse in this case, her action is structured by a sensitivity to the norms that constrain action (ethical, prudential, conventional). Importantly, she recognises that acting on the impulse would signify no violation of those norms. Acting on the impulse may involve no conscious decision, and it certainly doesn't involve any deliberation (recall: we are imagining a case in which the embrace is a direct expression of an impulse). Nonetheless, the expression of the impulse is measured. Although there is no strategic reasoning involved, it is a spontaneous act that is rooted in the agent's recognition of - and a sensitivity to - the norms that govern human interpersonal interaction. In sum, the agent is appropriately and reliably attuned to the normative constraints on action. Against this background, the embrace seems to be a substantive voluntary action, even if it is an expression of an impulse.

By contrast, in the absence of this background, i.e. without an appropriate attunement to the normative constraints that govern interpersonal interaction, an agent's expression of the impulse seems not to be measured. It seems rather to be driven entirely by the force of the impulse (it is, we might say, a wanton expression of the impulse). In this particular example, we can consider the contrast between measured and wanton expressions of an impulse in slightly more concrete terms by reference to a relevant conventional constraint: the agent who expresses her impulse in a wanton manner, let us suppose, either fails to recognise the standard of personal physical boundaries generally upheld by members of her community, or grasps that standard in a theoretical sense but systematically fails to be moved by it (for convenience, I'll elaborate the example in terms of the former condition). If the agent is systematically disposed to act on impulses whilst being wholly oblivious to this standard, then the expression of these impulses — whether they happen to coincide with or violate the standard — cannot be said to be 
measured or contained by an attunement to this standard. The agent is just as likely to act upon the impulse to hit a person, as she is to act upon the impulse to embrace him or her. This obliviousness is what makes the expression of her impulse wanton, and because this obliviousness limits the volitional resources available to the agent (her phenomenological field is filled up entirely by the impulse, the conventional standard of interpersonal boundaries being wholly absent from the field), the impairment operative in her wanton expression is distinctive: it signifies not just recklessness on the part of the agent (as the failure to be measured in one's impulsive expressions can sometimes be), but more fundamentally, it signifies a failure to exercise voluntary agency in a substantive sense. ${ }^{\mathrm{xi}}$

V. Behaving otherwise than usual: evidence of choice and control?

At the start of this paper, I reviewed Pickard's defence of the claim that PD-impulsive behaviours are voluntary. An important consideration in this defence is the fact that, when incentivised (or disincentivised), PD-impulsive subjects behave otherwise than they would, were the incentive not present. In other words, they would behave impulsively - as they normally do - were it not for the presence of the incentive on this occasion. Pickard frames this datum in terms of choice: she describes PD-impulsive subjects as "routinely choosing to behave otherwise." Thus, for instance, a PD-impulsive subject who would normally have impulsively stolen an item from his favourite games store does not, on this occasion, do this because of the presence of a policewoman standing close by to him. Pickard would take this to mean that the subject is exercising choice (i.e. he is choosing not to steal an item from the shop on this occasion) and exerting control over his behaviour in light of this choice. This way of interpreting the scenario becomes problematic in view of the foregoing discussion, however. 
To appreciate the difficulty, consider a familiar point that has been made about the susceptibility of impulse-driven behaviour to incentives. It has often been noted that this susceptibility to incentives does not provide conclusive evidence that such behaviour is under the control of the agent, because it could suggest instead that the agent is in the grip of competing impulses or urges. The classic example is of the agoraphobic person who musters the strength to leave his house when the building is ablaze. Here, the agent's extreme fear of leaving the house is pitted against his mortal fear of fire and being burned alive. The fact that he does manage to leave the burning building does not show that he did, in this particular case, make a choice and exercise choice-informed control over his agoraphobic-driven behaviour. No choice was made at all. What happened, rather, is that that one impulse or urge outweighed another in strength (Gary Watson draws attention to this point in various places. See Watson 2001. See also his 2004). Analogously, if the PD-impulsive subject's impulse to steal an item is, on a particular occasion, outweighed in strength by his fear of being caught and punished, then he may be propelled by the fear to not steal the item. In being so propelled, he does not make a choice not to steal the item, and so cannot be said to exert choice-informed control over his impulse to steal it.

None of this is to say that the impulsive behaviours constitutive of PD-impulsivity should be construed as compulsions. It may be that there are very different mechanisms in play in the two kinds of case (e.g. PD impulses and addictive compulsions). All I am suggesting is that the concept of choice may not be the most suitable one in terms of which to frame the datum being discussed, in view of the availability of an alternative interpretation that does not rely on the concept, combined with the fact that PD-impulsive subjects are dispositionally impulsive (which suggests either reason-blindness or reason-insensitivity on the part of the PD subject). This provides grounds for doubting the claim that, in behaving otherwise than he normally would in the presence of a (dis)incentive, what the PD-impulsive subject is doing is exercising 
choice-informed control over this (PD) behaviour. To doubt this claim is to doubt Pickard's main argument for the claim that PD behaviours are voluntary actions.

VI. Concluding remarks

Against Pickard's claim that PD behaviours are voluntary actions, I have made two points: first, the mere fact that PD-impulsive behaviours are not brute bodily movements does not, by itself, provide conclusive grounds for holding that they amount to actions done voluntarily. Second, I have put forward one reason for thinking that PD-impulsive behaviours are not voluntary actions, at least not on a substantive reading of this term. An agent's engagement in reason-giving practices is an important consideration: the visibility of reasons to the agent and their motivating force determines the extent to which an act — any act — arising out of the complex stew of the human psyche may properly be viewed as expressive of voluntary agency. This way of looking at the structure of agency that underpins PD-impulsive behaviours underscores the ways in which PD-impulsive behaviours are similar to, but importantly, different from, ordinary adult behaviour.

Jonathan Glover, in reviewing his interviews with patients at Broadmoor Hospital (a highsecurity psychiatric hospital in the UK), observes that the moral landscape of many of those he interviewed is "hard and narrow", a landscape in which an imaginative concern for others is not central (Glover 2014: 36). Most of Glover's interviewees are people "whose moral and emotional growth has been stunted" (ibid: 74). Exactly why and how this stunting happens are questions that are now the subject of intense empirical investigation. Glover himself notes that 
"emotional rejection, lack of recognition, blinkers, and the defensive wall" are recurrent features in the lives of those he interviewed. (ibid: 84) These conditions may well obscure reasons for action to the PD-impulsive agent, reasons that are visible and that carry motivational force for non-clinical agents. Without being able to see these reasons and/or to be suitably moved by them, the PD-impulsive agent is in effect deprived of an essential resource required for the exercise of voluntary agency, namely the capacity to recognise reasons for what they are and to be guided by them in action.

To conclude, the structure of agency in PD-impulsive agents is distinctive and this distinctiveness needs to be appreciated in determining whether PD-impulsive behaviours are voluntary or otherwise. By recognising that there is a specific sense in which such behaviours may be said to be voluntary, but that there is another sense in which they may not be voluntary, we begin to appreciate the depth and the richness of our ordinary notion of voluntary action. Understanding the distinctive structure of agency manifest by PD-impulsivity also enables us to gain a better insight into exactly what contribution is made by successful therapeutic strategies (such as mentalization and the cultivation of empathic imagination), and for understanding the ways in PD-impulsive subjects change as they adopt these strategies and incorporate them into an increasingly well-developed set of rational capacities. ${ }^{\text {xii }}$ 
References

American Psychiatric Association (APA) 2013. DSM V

Ayob, G. and Thornton, T. 2014. Psychopathy: What apology making tells us about moral agency. Theoretical Medicine and Bioethics, 35: 17-29

Buss, S. 1999. What practical reasoning must be if we act for our own reasons. Australasian Journal of Philosophy, vol. 77 (4), 399-421

Elster, Jon. 1999. Alchemies of the mind. Cambridge: Cambridge University Press.

Fischer, J. and Ravizza, M. 1998. Responsibility and control: A theory of moral responsibility. Cambridge: Cambridge University Press.

Frankfurt, H. 1971. Freedom of will and the concept of a person. Reprinted in Frankfurt 1988

- 1988. The importance of what we care about. Cambridge: Cambridge University Press

Glover, J. 2014. Alien landscapes: Interpreting disordered minds. Cambridge, Massachusetts: Harvard University Press

Greenspan, P. 1988. Emotions and reasons: An inquiry into emotional justification. New York: Routledge.

- 2004. Practical reasoning and emotion. Oxford Handbook of Rationality. Mele and Rawlings (eds.). Oxford: Oxford University Press, 206-221.

Kavoussi, Richard and E. Coccaro 1996. Biology and pharmacological treatment of impulsecontrol disorders. Impulsivity and Compulsivity. Oldham, Hollander, and Skodol (eds.) American Psychiatric Press.

Leonardi, R., Vick, S., and J. Dufour. 2012. Waiting for more: the performance of domestic dogs on exchange tasks. Animal Cognition, vol. 15, 107-120

Oltmanns, Thomas and M. Martin, J. Neale, G. Davison 2012. Case studies in abnormal psychology. Hoboken, NJ: Wiley

Patton, Stanford, and E. S. Barratt 1995. Factor structure of the Barratt Impulsiveness Scale. Journal of Clinical Psychology 51, 768-774

Pickard, H. 2011. Responsibility without blame. Philosophy, Psychiatry, Psychology, vol.18 (3), 209-223

- 2013. Responsibility without blame: philosophical reflections on clinical practice. Oxford Handbook of Philosophy and Psychiatry, in eds. Fulford, Davies, Thornton, 1134-1152. Oxford: Oxford University Press.

Smith, M. 2003. Rational capacities, or: how to distinguish recklessness, weakness, and compulsion. Weakness of will and practical irrationality, eds. Stroud and Tappolet. Oxford: Oxford University Press 
Strawson, P. 1974. Freedom and resentment. Reprinted in Strawson 1988.

\title{
- Strawson, P. 1988. Freedom and resentment and other essays. London: Routledge
}

Wallace, R.J. 1988. Responsibility and the moral sentiments. Cambridge, Massachusetts: Harvard University Press

Watson, G. 2001. Reasons and responsibility. Ethics, vol.111, 374-394

- 2004. Agency and answerability: Selected essays. Oxford: Oxford University Press

Wolf, S. 1990. Freedom within reason. Oxford: Oxford University Press

\begin{abstract}
i A further terminological note: Pickard claims that PD behaviours are voluntary, without referring specifically to impulsive acts when making this claim. As PD-impulsive behaviours are a subset of this category, I take it that her claim applies to this subset, just as it does to other types of behaviour taken to be diagnostic of PD.

ii In the DSM V, diagnostic criterion A3 for Antisocial Personality Disorder refers specifically to the "failure to plan ahead". The examples given to illustrate the impulsivity criterion for Borderline Personality Disorder (A4) are all behavioural (none are attentional), e.g. spending, sex, reckless driving. (APA 2013). For the distinction between attentional impulsivity and volitional impulsivity, see Patton, Stanford, and Barratt 1995.

iii In the penultimate section of the paper (Section V), I question whether choice is the most suitable concept in terms of which to frame the datum that Pickard speaks of here. The datum is this: when suitably incentivised, PD subjects do behave otherwise than they would behave in the absence of the incentive (i.e. the incentiveabsent behaviour is PD behaviour). But it is a substantive question whether this datum ought to be framed in terms of the concept of choice, as I hope this paper will show. If it turns out that there are strong grounds for doubting the suitability of the concept of choice in the interpretation of this datum, then this significantly weakens Pickard's main argument for the claim that PD behaviours are voluntary actions.

iv A terminological note: I will use the term 'impulse' and 'urge' interchangeably, and I take the term 'PDimpulsivity' to refer to the disposition to act on one's urges/impulses in the sense outlined in Section II. "Emotions, usually painful and difficult ones, are understood to play an important motivating role especially in $B P D$, so it is worth saying something about how emotions relate to this schema of behavioural types. Emotions are one of several sources of human motivation (other sources include appetites, desires and intentions, the latter of which may arise from emotions, but do not necessarily do so). Emotional states may be a source of motivation in instances of behaviour in behavioural types (iv) to (vi). While it is generally accepted that emotions can directly motivate impulses and urges with intentional content ((iv) above), philosophers are divided over whether emotions can serve as reasons for action in their own right. In other words, there is disagreement about whether acts motivated solely by emotions-bypassing belief-desire reasoning-ought to be conceived of as intentional actions (a fortiori as autonomous actions). Jon Elster excludes emotions from the category of mental states that can be rational, on the grounds that emotions are typically unchosen and that rationality can be a feature only of choice (Elster 1999, Chapter 4). This view might lead one to place emotions outside the domain of practical reasoning, thereby excluding any act motivated solely by emotionunmediated by desires and beliefs - from counting as an instance of behavourial type (v) or (vi). By contrast, Patricia Greenspan includes emotions within the category of mental states that can be rational (see Greenspan 1988). Furthermore, she takes the scope of practical reasoning to be wider than means-ends reasoning, to include actions expressive of emotion, which she notes is valuable to the agent as "the completion of a more integrated psychological whole: a fit between inner and outer states of oneself." (Greenspan 2004). So Greenspan would presumably be open to the view that behavioural type ( $v$ ) has two variants: actions determined by belief-desire pairings (with or without an affective element) and actions determined solely by emotions. This debate about the position of emotions in practical reasoning is an important one, but it isn't of immediate relevance to the present discussion since our concern here is with impulsive acts only (acts of type (iv)).

vi That being the case, the idea that a token, one-off piece of behaviour could be voluntary by luck is not intelligible. Of course, to successfully execute an intended action depends on empirical fortune. But this latter point is about execution of the act, as distinct from the constitution of the act itself
\end{abstract}


vii A point of clarification: to deny that rational capacities are present (or to suggest that they are seriously underdeveloped) is not to deny the potential in the PD-impulsive agent for instantiating those capacities. viii Susan Wolf (1990) is a prominent advocate of the former view; Harry Frankfurt adopts the latter position. ix Elsewhere, I have argued that, in the case of psychopathy, there is reason for thinking that the psychopathic subject is blind to reasons, rather than that he fails to be suitably motivated by the reasons he perceives aright. (Ayob and Thornton 2014)

${ }^{x}$ This concludes my argument for the claim that the stability of the trait of impulsivity in PD agents gives us grounds for holding that these agents suffer from a capacity failure (specifically, that they lack the normative competence essential to voluntary agency). A discussion of the mechanisms that underpin this capacity failure will provide an important source of corroboration, but the framing of any such mechanism will depend on the foregoing argument. We first need to recognise the bearing that dispositional impulsivity has on the determination of an agent's normative competence, before being able to view the mechanisms that contribute to dispositional impulsivity (e.g. a lack of empathic concern for others, in APD) as having a capacityundermining significance.

${ }^{x i}$ Although the distinction between recklessness, weakness of will, and compulsion was originally discussed in the context of deliberated actions (hence Smith's reference to reasons), the notion of recklessness seems to be applicable to those aspects of agency in which attunement to normative constraints is essential, regardless of whether that attunement is made manifest in deliberation or in a more automatic way. Recklessness in the latter sense would mean that the agent is attuned to the relevant normative constraints that prescribe a withholding of the expression of an impulse, say, but that she knowingly disregards those constraints and expresses the impulse anyway. The idea of knowingly disregarding normative prescriptions shouldn't be taken to entail that deliberation is involved, since the following type of case is most naturally described without having to invoke the notion of agent deliberation: someone's raising their voice in anger in a corridor, in spite of knowing full well that an examination is in progress in a hall along the corridor ( $\mathrm{l}$ am assuming that this person is aware of the conventional norm to speak quietly in the vicinity of examination halls, and that he normally abides by this norm). Raising his voice was a reckless thing for the agent to do, even though it involved no act of deliberation on his part.

xii This paper has not touched upon the connection between the capacity for voluntary agency and the prospect of personality development. In defending the claim that PD agents act voluntarily, one of Pickard's main concerns seems to be to uphold an optimistic stance towards the prospect of such change. I share Pickard's concern, although I do not think optimism rests on a prior commitment to viewing the acts of PD agents as voluntary. Their being involuntary does not entail that a PD agent's predicament is fixed and invariant to appropriate interventions. All it means is that, prior to such interventions and the growing responsiveness to reasons that they bring about, the lack of traction of reasons in the PD-impulsive agent's life is grounds for holding that PD-impulsive acts are not expressive of voluntary agency. 